

\title{
Arte El ejercicio del criterio. La recepción de la crítica de arte de José Martí en el siglo XX latinoamericano
}

\author{
Luis Sihuacollo \\ Universidad Nacional Mayor de San Marcos \\ luis.sihuacollo@gmail.com
}

\begin{abstract}
Criticar no es morder, ni tenacear, ni clavar en la áspera picota, no es consagrarse impíamente a escudriñar con miradas avaras en la obra bella los lunares y manchas que la afean; es señalar con noble intento el lunar negro, y desvanecer con mano piadosa la sombra que oscurece la obra bella.
\end{abstract}

José Martí1

\begin{abstract}
Resumen
Escritor, poeta, orador, catedrático, periodista, agente consular, estadista, crítico de arte y de literatura, José Martí (1853-1895) es al mismo tiempo el patriota que organizó las bases para la independencia de Cuba en las postrimerías del siglo XIX. Su crítica de arte, que él llamó "ejercicio del criterio", no fue examinada sino hasta mediados del siglo XX, pues el apremio por conferirle a Cuba una identidad nacional hizo que brillara por mucho únicamente su genio político. Juzgó la obra de artistas latinoamericanos, norteamericanos y europeos, y fue el primero en calificar como arte la producción espiritual de "nuestra América" antigua. Su visión de la realidad artística latinoamericana se articuló dentro de una concepción general que buscó reconfigurar el objeto de la estética reinante con la finalidad de incorporar en ella las creaciones de todos los pueblos del mundo. Las siguientes páginas, que forman parte de un trabajo mayor sobre el pensamiento estético de Martí, abordan brevemente la recepción de su crítica de arte en el siglo XX latinoamericano.
\end{abstract}

Palabras clave: José Martí, crítica de arte, ejercicio del criterio, siglo XX latinoamericano.

\begin{abstract}
Writer, poet, speaker, professor, journalist, consular agent, statesman, art and literature critic, José Marti (1853-1895) is at the same time the patriot who organized the basis for the independence of Cuba in the late nineteenth century. His art criticism, which he called "exercise of the criterion", was not examined until the mid-twentieth century, because the pressure to confer a national identity on Cuba made his political genius shine by far. He judged the work of Latin American, North American and European artists, and was the first to qualify as art the spiritual production of our "ancient America". His vision of the Latin American artistic reality was articulated within a general conception that sought to reconfigure the object of the prevailing aesthetic with the purpose of incorporating in it the creations of all the peoples of the world. The following pages, which are part of a larger work on Marti's aesthetic thinking, briefly address the reception of his art criticism in the Latin American XX century.
\end{abstract}

Keywords: José Marti, art critic, exercise of the criterion, Latin American XX century.

1 Martí, J. (1975). Obras completas. 27 volúmenes. Segunda edición. La Habana: Instituto Cubano del Libro y Editorial de Ciencias Sociales. En adelante citaremos esta edición empleando números romanos para señalar el volumen y arábigos para indicar la página: (XV, p. 94). 


\section{El escenario}

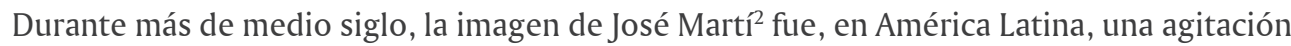
política con tintes de religión. Esta visión estuvo marcada por su temprana y dramática desaparición, pues ella suponía la pérdida del maestro que encaminaría al pueblo cubano rumbo a su legítima independencia ${ }^{3}$. Pero esta no fue la única razón. Al año siguiente, en la velada póstuma que la Sociedad Literaria Hispanoamericana celebró a su nombre en Nueva York, Enrique José Varona dejaba caer estas palabras: "Para ver y abarcar desde un punto central la existencia tan accidentada de este grande hombre, nada es tan adecuado como considerar su labor política. Esta es la esencia; las demás fases de su vida pública son detalles y accidentes"4. De este modo se ungía la figura del revolucionario por sobre los demás ámbitos de su fecunda y heterogénea creación.

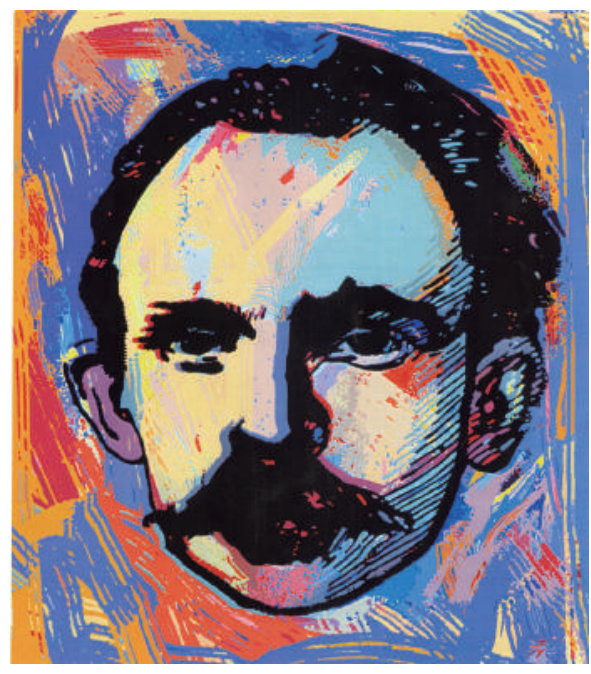

M. Velaochaga. José Martí. 2013. Serigrafía, $23 \times 19 \mathrm{~cm}$

Por supuesto, existieron otros factores. En 1901 se publicó en La Habana un anónimo folletín titulado Martí. Novela histórica por un patriota. En esta biografía inaugural, cuyo valor es más documental que estético, Martí fue bautizado como "Apóstol" por la tarea política que desempeñó fuera de Cuba. Desde entonces, comenzó una larga difusión de libros y actividades que exaltaron su imagen hasta extremos fantásticos: organizaban cultos en que pan y vino simbolizaban su cuerpo y sangre, o incluso recitaban un solemne Padrenuestro martiano. Más tarde, durante la dictadura de Gerardo Machado (1925-1933), la figura de Martí fue revestida con un halo ideológico que buscaba ubicarlo en las filas del marxismo. Diversos autores emprendieron, entonces, la tarea de familiarizar sus ideas con el materialismo dialéctico o con el comunismo más radical. No faltó, a su vez, quien lo tachara de anticomunista y antiproletario. Por esa misma época, y en medio de tales acrobacias intelectuales, fue asomando fuera de la Isla el interés por estudiar su obra literaria. Rubén Darío, Miguel de Unamuno, Alfonso Reyes, Juan Ramón Jiménez, Gabriela Mistral, entre otros, ayudaron a redescubrir esta faceta que hasta entonces había quedado ensombrecida por la general atención que la hagiografía martiana había prestado al aspecto político. Para

2 Para un completo alcance biográfico, revisar Mañach, J. (1933). Martí. El Apóstol. Madrid: Espasa-Calpe; García, R. (1938). Martí. Biografía familiar. La Habana: Cárdenas y Cía.; Lizaso, F. (1940). Martí. Místico del deber. Buenos Aires: Losada; Rodríguez Embil, L. (1941). Martí. El santo de América. La Habana: Fernández y Cía.; Magdaleno, M. (1941). José Martí (Fulgor de Martí). México: Ediciones Botas; Zacharie de Baralt, B. (1945). El Martí que yo conocí. La Habana: Editorial Pueblo y Educación; Méndez, I. (1947). Martí. Documentos para su vida. La Habana: Archivo Nacional de Cuba; Baeza Flores, A. (1954). Vida de José Martí. El hombre íntimo y el hombre público (Premio Nacional en el concurso del mejor libro biográfico inédito sobre José Martí). La Habana: Publicaciones de la Comisión Nacional Organizadora de los Actos y Ediciones del Centenario y del Monumento de Martí; Márquez Sterling, C. (1973). Biografía de José Martí. Barcelona: Imprenta Manuel Pareja; Hidalgo Paz, I. (1992). José Martí. Cronología. La Habana: Centro de Estudios Martianos; Toledo Sande, L. (1996). Cesto de llamas. Biografía de José Martí. La Habana: Editorial de Ciencias Sociales.

3 Existe en Cuba -aunque su origen aún se discute- una obra musical llamada Clave a Martí, que recoge este lamento: "Aquí falta, señores, iay! una voz / de ese sinsonte cubano, / de ese mártir hermano / que Martí se llamó. / Martí no debió de morir. / Si fuera el maestro y el guía, / otro gallo cantaría, / la patria se salvaría / y Cuba sería feliz".

4 El discurso de Varona fue reproducido fragmentariamente por Gonzalo de Quesada y Miranda en el conjunto de testimonios Así vieron a Martí (Quesada, 1971, pp. 302-305), bajo el título breve: “José Martí”. Dos años después, la revista Casa de las Américas publicó íntegramente el discurso en su sección "Documentos" (1973, pp. 91-95), con el título original que ideó Varona: "Martí y su obra política". 
entonces, ya se habían publicado las primeras ediciones de sus obras completas, organizadas por su discípulo y albacea literario, Gonzalo de Quesada y Aróstegui ${ }^{5}$. Las cátedras y seminarios para difundir el pensamiento de Martí llegarían con el ascenso al poder de Fulgencio Batista (1940-1944). Este mismo encabezaría, ocho años después, el golpe de Estado que lo aseguraría en el Gobierno hasta la irrupción de Fidel Castro en 1959. Este nuevo período en la historia cubana no estuvo a salvo de los artificios de la imaginación. Un poeta creyó ver en los versos de Martí ("Cultivo una rosa blanca / En julio como en enero") una prefiguración del 26 de junio y del 1 de enero de Fidel, fechas de capital importancia para Cuba ${ }^{6}$. Así, entre idas y vueltas, la imagen del "Apóstol”, "Santo", "Mártir" y "Revolucionario" siguió siendo utilizada a discreción, pero aquella figura falseada se hacía cada vez menos verosímil. En las últimas décadas, el análisis ha sucedido a las piadosas letanías que se recitaban tras el nombre de Martí, y aquella cándida lectura que rayaba lo sagrado se esfuma ante la energía crítica de una generación que no se contenta con una afirmación dulzona y simplista.

\section{Félix Lizaso y Gonzáles ${ }^{7}$}

La primera referencia al tema de la crítica de arte en José Martí la hallamos en el libro Vida y pensamiento de Martí, publicado en dos tomos hacia 1942 por el cubano Félix Lizaso. En él hay un capítulo titulado "Martí, crítico de arte", el cual, más que reparar en el análisis de sus juicios artísticos, se concentra en esclarecer las circunstancias que hicieron de él un perito en cuestiones de arte. Lizaso sostiene que fue en Zaragoza donde Martí sintió la impresión de la gran pintura y comenzó su simpatía por el tema. Recordemos que a los dieciséis años, acusado de infidencia, Martí fue detenido y más tarde condenado al presidio político. La pena le fue conmutada por el destierro a España, en donde siguió los estudios en derecho y filosofía (primero en Madrid y luego en Zaragoza). Esta temporada española, reitera el autor, despertó su curiosidad por las artes plásticas, pues “de pintura nada podría conocer, ya que nuestra carencia de museos no le había permitido siquiera la contemplación de obras artísticas" (Lizaso, 2007, p. 82). Pero aquella vocación tampoco pudo surgir por la sola visita a los museos. Hubo algo más. Lizaso se apoya en el testimonio que dejó Fermín Valdés Domínguez, íntimo amigo de Martí, y sugiere que la amistad cultivada con el pintor Pablo Gonzalvo fue determinante en su formación: "La frecuente concurrencia al taller del pintor [Gonzalvo] habría de proporcionar a Martí lo que solo puede adquirirse de ese modo cuando no se realizan estudios metódicos: un conocimiento íntimo de los manejos de la pintura” (Lizaso, 2007, p. 83).

5 Fechada el 1 de abril de 1895, desde Montecristi, Martí escribe la carta que ha sido considerada como testamento literario. En ella indica a su "Gonzalo querido" que, además del tomo que recoja su Ismaelillo, sus Versos sencillos y "lo más cuidado o significativo" de sus Versos libres, ordene sus papeles en los siguientes volúmenes: I. Norteamericanos; II. Norteamericanos; III. Hispanoamericanos; IV. Escenas norteamericanas; V. Libros sobre América; VI. Letras, Educación y Pintura (I, pp. 25-28). De este modo, entre 1900 y 1915 , Gonzalo de Quesada y Aróstegui editó en catorce volúmenes las primeras Obras completas de Martí. El volumen quince apareció en 1919. Más tarde, en 1933, Gonzalo de Quesada y Miranda, continuando la labor de su padre, publicó un último tomo, con el que se cerró esta primera colección. Néstor Carbonel publicó entre 1918 y 1920 unas Obras completas de Martí en ocho tomos. El argentino Alberto Ghiraldo entregó a la imprenta, entre 1925 y 1929, y también en ocho tomos, unas Obras completas del cubano. Pocos años después, la Editorial Trópico, a cargo de Quesada y Miranda, inició la publicación de sus Obras completas en 74 tomos. Asimismo, la Editorial Lex entregó, en 1946, dos volúmenes que recogían todo lo que hasta entonces Martí había escrito. El historiador cubano Carlos Ripoll sostiene que sólo pueden llamarse "obras completas" las ediciones de Trópico y Lex, pues las anteriores no llegaron a terminarse. Por otro lado, entre 1963 y 1966, la Editorial Nacional de Cuba publicó unas Obras completas en 27 volúmenes. Existe una segunda edición de la misma (la que sirve de guía al presente trabajo). Finalmente, desde el año 1983 y bajo la dirección de Pedro Pablo Rodríguez, el Centro de Estudios Martianos viene publicando las Obras completas, edición crítica de José Martí. Este proyecto fue iniciado por los estudiosos martianos Cintio Vitier y Fina García-Marruz, y actualmente cuenta ya con 28 tomos.

6 Incluso la popular Clave a Martí, que antes citamos, ya no cantará más la pena por su muerte, sino que, modificada la letra, exaltará en adelante el triunfo de la revolución: "Martí ahora vuelve a vivir. / Hoy es el maestro y el guía: / la revolución inspira, / a Fidel sirve de guía / y mi Cuba ya es feliz".

7 Historiador y ensayista cubano (1891-1967). 
Sin embargo, la importancia de Gonzalvo -anota Lizaso- se limitó solo a proveer a Martí de una serie de conocimientos técnicos e ideas generales, pues su obra "convencional" y "poco expresiva”, difícilmente pudo producirle goce estético. Resulta curiosa esta valoración que de Gonzalvo se realiza, ya que el propio Martí lo juzgó de "concienzudo" y dijo de aquel: "Yo conocí a Gonzalvo, cuando con mano magistral ponía en el lienzo, a la luz de la mañana de verano sorprendidos, los esplendores rojos del sol [...]" (XV, p. 140). Lizaso continúa el recorrido y se detiene a comentar la posterior etapa mexicana de Martí, en la que inició estrictamente su labor como crítico de arte. Efectivamente, Martí llegó a México en 1875, cuando entonces gobernaba Sebastián Lerdo de Tejada. Sin duda, debió ser enorme la impresión que le causó esta República democrática y liberal en contraste con el atraso en que se hallaba su patria, pues Lerdo de Tejada había inaugurado en 1873 el ferrocarril que unía México a Veracruz, y al mismo tiempo enviaba científicos mexicanos al Japón para destacar su presencia en el ámbito internacional. En marzo de ese mismo año, Martí inició su colaboración en la Revista Universal de Política, Literatura y Comercio, y sus textos se publicaron junto a los de Guillermo Prieto, Manuel Altamirano, Ignacio Ramírez, Justo Sierra y Juan de Dios Peza, entre otros.

Es cierto que Martí fue el más insistente en reclamar un arte propio (mexicano, latinoamericano) que cortara con los modelos europeos y expresara en sus creaciones la historia nacional, pero Lizaso, como ya hemos señalado, no quiere dictaminar sobre la validez de los juicios martianos, sino que está interesado en mostrar el proceso de su formación como crítico de arte. De allí que considere valiosa su amistad con el pintor Manuel Ocaranza -quien mantuvo una relación con Ana Martí, su hermana-, pues asegura que "pasaba horas viéndolo pintar" en su taller ubicado en casa de Manuel Mercado. Producto de esta cercanía con el artista, se sugiere, sus conocimientos sobre arte fueron cada vez más refinados.

Posteriormente, con la intromisión política de Porfirio Díaz en el Gobierno mexicano a finales de 1876, muchos periódicos dejaron de publicar -entre ellos, la Revista Universal- y Martí se vio obligado a salir del país. Luego de una estancia en Guatemala, regresó a México (donde contrajo matrimonio con Carmen Zayas Bazán) y luego a Cuba, para después enrumbar hacia Nueva York, ciudad en la que, salvo los rápidos viajes que realizó a Venezuela, Santo Domingo, Jamaica, Panamá y Costa Rica, vivió hasta su muerte. Allí conoció a Carmen Miyares, su amiga y colaboradora en la causa independentista de sus últimos años. Comenta Lizaso las conversaciones que sobre arte se desarrollaban luego de las comidas entre Martí y el pintor Tomás Collazo, quien visitaba con regularidad a la familia: "Oyéndole hablar de sus impresiones en los museos de Europa, Collazo se sorprende de la gran disposición que como crítico de arte posee Martî" (Lizaso, 2007, p. 92); y un buen día lo sorprende con la noticia de que ha conseguido para él un trabajo como crítico de arte en la naciente revista The Hour.

Desde los Estados Unidos, Martí logró tener una visión más completa de la realidad latinoamericana, esa que llamó “nuestra América”, pero no solo del arte, sino de todo el entramado social, político y económico en general, lo cual enriquecerá su conciencia americanista ${ }^{8}$. De este modo, Lizaso presentó al mundo la labor crítica de Martí en cuestiones de arte. Este trabajo pionero consistió en registrar cronológicamente -acaso sería más exacto decir biográficamente- el adelanto que va logrando Martí mientras recorre museos y talleres de artistas, dialogando con ellos y observando atentamente las más diversas técnicas que esgrimían, asimilando todo cuanto se desplegaba frente a sus ojos para luego volcar toda esa experiencia en su "ejercicio del criterio".

8 Hans-Otto Dill ha diferenciado muy bien el americanismo de Martí del americanismo de Andrés Bello, Simón Bolívar y José de San Martín. El punto de separación está determinado precisamente por la experiencia norteamericana de Martí, pues fue allí donde pudo descubrir el subdesarrollo de "nuestra América". En adelante, su labor no buscará exclusivamente la liberación política y cultural, sino que un nuevo elemento será añadido al proyecto liberador: el progreso económico como medida de adelanto social (Dill, 1975). 


\section{Justino Fernández García ${ }^{9}$}

En 1951, Justino Fernández publicó su ensayo José Martí como crítico de arte. Se trató de un estudio riguroso apoyado en los dos tomos de las Obras completas de José Martí que la Editorial Lex publicó en La Habana en 1946, a propósito del cincuentenario de su muerte. Fernández se encargó de rastrear minuciosamente los textos que Martí dedicó a la crítica de arte y pudo presentar un cuadro completo de los mismos, tarea que Lizaso no pudo llevar a cabo debido a la escasez y poca difusión que en su tiempo tuvieron los textos martianos consagrados al arte ${ }^{10}$. En total, se cuentan 37 artículos redactados entre 1875 y $1894^{11}$-pocos meses antes de su muerte-, además de una serie de notas y referencias que dejó dispersas en cuadernos y cartas.

Fernández también recurrió al criterio cronológico, pero atendiendo exclusivamente a los textos y "excluyendo las circunstancias de la vida de Martí en que dio a luz un artículo u otro, a excepción de los datos más perentorios” (1951, p. 9). Al igual que Lizaso -y a pesar de no haber podido acceder a su investigación, según aclara en una nota-, este autor afirmó que "durante su primera estancia en España [Martí] conoció el gran arte" (Fernández, 1951, p. 10). Todos los artículos de Martí son aquí examinados al detalle, pasando por Goya, Madrazo, Fortuny, Cordero, Rebull, Velasco, Gutiérrez, Daumaine, Detaille, Delacroix, Fromentin, Courbet, Corot, Seurat, Manet, entre otros. Luego de realizar un comentario de cada uno de ellos, Fernández ofrece sus resultados de forma contundente: Martí demandaba, desde que se inició como crítico de arte, una "pintura mayor" de factura realista, que no logró hallar en su tiempo.

Este tipo de creación, por supuesto, respondía al gusto académico del propio Martí, a ese amor por la pintura realista que siempre exigió de los artistas latinoamericanos. De allí los elogios que siempre tuvo hacia la obra paisajística del mexicano José María Velasco: "Detengámonos y admiremos ese notabilísimo paisaje, tan bello como la naturaleza, espléndido como nuestro cielo, vigoroso como nuestros árboles, puro como las aguas apacibles de nuestra majestuosa laguna de Texcoco" (VI, p. 386). A su vez, Fernández anotó que las expresiones artísticas menos naturalistas fueron para Martí más difíciles de aceptar, como en el caso de los impresionistas (sobre todo Manet y Seurat): "¿Por qué afean su santo amor a lo verdadero con el culto voluntario de lo violento o lo feo?" (X, p. 439); y sostuvo que la pintura religiosa no formó parte de su idea de "la gran pintura", por el hecho simple de tratarse de un arcaísmo, un tema que no le pertenecía ya al siglo XIX: “Todo anda y se transforma, y los cuadros de vírgenes pasaron" (VI, p. 389). Finalmente, el autor evidencia un método en el modo en que Martí desplegó su crítica artística: "Primero da el trasfondo histórico de la escena; [luego] hace el retrato psicológico [de los personajes] (...); después, en movimiento, llevándonos de la mano, o más bien de los ojos (...), continúa su relato hasta dejar la instantánea en el cuadro frente al espectador; entonces, analiza [formalmente] la pintura" (Fernández, 1951, p. 14).

9 Historiador y filósofo mexicano (1904-1972).

10 "Han transcurrido muchísimos años desde ese día de abril de 1895 y de esos cuatro trabajos que el maestro señaló [para su publicación sobre artes en un tomo independiente]. El Dorador no se ha encontrado todavía ni sabemos dónde se halla. El Cristo de Munkacsy vino a más amplio conocimiento hace poco tiempo, cuando Néstor Carbonell lo dio de nuevo a la circulación, y el Vereschagin es todavía desconocido, aunque he tenido la suerte de que un amigo de Buenos Aires, el finísimo escritor Raimundo Lida, autor de una de las mejores antologías martianas que existen, oyera mis ruegos y me enviara el trabajo a tiempo en que terminaba la redacción de estas cuartillas" (Lizaso, 2007, pp. 81 y 82). El cuarto trabajo al que hace referencia el autor es la nota que Martí dedica a los pintores impresionistas.

11 Ocho artículos en la Revista Universal de México (1875); doce artículos en The Hour de Nueva York (1880); un artículo en La Opinión Nacional de Caracas (1882); nueve artículos en La América de Nueva York (18831884); cuatro artículos en La Nación de Buenos Aires (1886-1889); y tres artículos en Patria de Nueva York (1892-1894). 
Justino Fernández afirmó que en la etapa última de su vida, "Martí antepuso el ideal de la libertad a cualquier otro, inclusive al del arte; [y] que, en consecuencia, el temple moral del luchador por la libertad le pareció más admirable que el resultado artístico" (Fernández, 1951, p. 44). Sin duda alguna, esta enunciación fue motivada por el artículo que Martí dedicó al pintor ruso Vereschagin en 1889, en la que resuenan estas palabras: "ila justicia primero y el arte después! (...) Cuando no se disfruta de la libertad, la única excusa del arte y su único derecho para existir es ponerse al servicio de ella. iTodo al fuego, hasta el arte, para alimentar la hoguera!” (XV, p. 433). El año de 1889, según nuestro autor, marcó el cambio en la estimativa martiana. La ética, entonces, fue el eje rector que decidió sus juicios artísticos. Justino Fernández termina su ensayo indicando que a otros queda la tarea de establecer las conexiones entre la crítica de arte y el pensamiento de Martí.

\section{Roberto Fernández Retamar ${ }^{12}$}

En 1972, este autor realizó una compilación de los artículos que Martí dedicó a la crítica literaria y artística. Esta selección fue publicada con un estudio breve, a modo de prólogo, titulado "Sobre la crítica de Martí". Allí sostuvo que, al igual que otros escritores modernistas $^{13}$, Martí compartió ciertos caracteres del llamado impresionismo, pero que en él "la crítica verdadera no está nunca sofocada, o siquiera estorbada, por el brillo impresionista" (Fernández Retamar, 1972, XI). No obstante, este autor se detiene más en el asunto literario y casi por extensión se refiere al artístico. Se trata de una apreciación general que no pretende ser minuciosa, pero que por abordar el tema de la crítica de arte -aunque panorámicamente-comentamos ahora.

Entre otras cosas, el autor señaló que la crítica martiana debe ser entendida a partir la función que cumplió en el contexto histórico específico del siglo XIX, cuando la carencia de un arte propio latinoamericano suponía la falta de una identidad propia; por eso su constante prédica de una obra genuina que asuma la historia americana como tema de creación pictórica. Asimismo, resaltó la labor martiana de injertar la cultura mundial a nuestras repúblicas, ya que Martí "nos pone en relación crítica con el arte y la literatura de España y Francia, los Estados Unidos y Rusia, Inglaterra y Hungría, e indirectamente con creaciones hindúes, griegas, latinas o alemanas" (Fernández Retamar, 1972, XV). Este aspecto también fue subrayado por Juan Ramón Jiménez, quien registró a Martí como el introductor de la obra de Whitman a España (Jiménez, 2007, p. 63).

Por otro lado, y coincidiendo con Justino Fernández, advierte un cambio en el pensamiento de Martí, que entiende más bien como una evolución, pero como no busca polemizar sobre la fecha que pudiera fungir de bisagra ideológica, anota simplemente que debió darse entre finales de la década de 1880 y principios de 1890, básicamente motivada por la preparación de la "guerra necesaria". Rine Leal también ha considerado la preeminencia de la ética por sobre la estética en los juicios martianos dedicados al teatro, pero a diferencia de Justino Fernández y Roberto Fernández Retamar, identificó esta inclinación desde su adolescencia, pues Martí "será siempre el crítico revolucionario que presta atención y destaca el aspecto político por encima del artístico puro" (Leal, 1981, p. 29). No obstante, Winston Orrillo ha señalado que este aparente conflicto se resuelve apelando a la idea del "arte nuevo" latente en el ideario martiano: "un arte, en fin, que tendrá como base la íntima unidad entre ética y estética” (Orrillo, 2008, p. 211).

12 Filósofo, poeta y ensayista cubano (1930).

13 A propósito de la discusión en torno a la filiación modernista de Martí, revisar Marinello, J. (1959). Sobre el Modernismo. Polémica y definición. México: Universidad Nacional Autónoma de México. 
A la par de estos trabajos, podemos mencionar los de Adelaida de Juan Seiler ${ }^{14}$ : José Martí y el arte mexicano y Arte y entorno en Nueva York según Martí, en los que, siguiendo los juicios de Justino Fernández y Roberto Fernández Retamar (su esposo), desarrolló un aspecto poco atendido dentro de la obra de Martí: el de la "promoción de la obra de arte" latinoamericana y sus relaciones con el mercado de los Estados Unidos. Asimismo, tenemos la obra monumental que publicó en tres volúmenes Ida Rodríguez Prampolini ${ }^{15}$ : La crítica de arte en México en el siglo XIX. Estudios y documentos. En el primer volumen encontramos un estudio sobre "Los principios de la crítica de arte", dividido en dos periodos: entre 1810 y 1860 (el primero), y entre 1860 y 1900 (el segundo). En este último, y siguiendo en gran medida las conclusiones que dejó Justino Fernández en el ensayo ya comentado, se presenta a Martí en contraste con otro crítico de arte de la época, Felipe López López, quien simbolizaría la racionalidad de gusto clásico, mientras que Martí, más joven, sensible e intuitivo, encarnaría la posición crítica "más tolerante, comprensiva y quizá, sería posible decir, humanizada” (Rodríguez, 1997, p. 144).

Todos estos estudios, y quizá agregando el capítulo VII del libro Vida y obra del Apóstol José Martí de Cintio Vitier, titulado "Crítica"16, suponen la recepción crítica de la obra martiana en cuestiones de arte para el siglo XX. Hemos querido apenas esbozar en líneas muy generales el derrotero que ellas han seguido desde su incorporación a la historiografía. Sin embargo, queda todavía por escribir la obra orgánica que sistematice su pensamiento estético, pues la crítica de arte en Martí, entendemos, es la manifestación viva de una idea mayor que se integra a una concepción general del mundo.

\section{Referencias bibliográficas}

De Quesada, G. (1971). Así vieron a Martí. La Habana: Instituto Cubano del Libro.

Dill, H. (1975). El ideario literario y estético de José Martí. La Habana: Casa de las Américas.

Fernández, J. (1951). José Martí como crítico de arte. En Anales del Instituto de Investigaciones Estéticas. N. ${ }^{\circ} 19$, México: UNAM, pp. 7-48.

Fernández Retamar, R. (1972). Sobre la crítica de Martí. En José Martí, ensayos sobre arte y literatura. La Habana: Instituto Cubano del Libro.

Jiménez, J. (2007). José Martí. En José Martí. Valoración múltiple. La Habana: Centro de Investigaciones Literarias y Casa de las Américas, pp. 63-65.

Juan, A. de (2003). Arte y entorno en Nueva York según Martí. En José Martí en los Estados Unidos. Periodismo de 1881 a 1892. Barcelona: PUCP, pp. 1978-1991.
Hidalgo, I. (2003). José Martí 1853-1895. Cronología. Segunda edición. La Habana: Centro de Estudios Martianos.

Leal, R. (1981). Martí y el teatro. En Teatro. José Martí. La Habana: Centro de Estudios Martianos y Editorial Letras Cubanas.

Lizaso, F. (1942). Martí, crítico de arte. En Vida y pensamiento de Martí. Tomo I. La Habana: Ediciones Municipio de La Habana.

Martí, J. (1975). Obras completas. 27 tomos. Segunda edición. La Habana: Instituto Cubano del Libro y Editorial de Ciencias Sociales.

Orrillo, W. (2008). Martí - Mariátegui. Literatura, inteligencia y revolución en América Latina. Lima: Fondo Editorial Educap.

Varona, E. (1973). Martí y su obra política. En Casa de las Américas, N. ${ }^{\circ}$ 76. La Habana: Instituto Cubano del Libro, pp. 90-95.

Recibido el 18 de septiembre del 2018

Aceptado el 28 de septiembre del 2018

14 Filósofa y ensayista cubana (1931-2018).

15 Historiadora mexicana (1925-2017).

16 Las reflexiones de este capítulo repasan en gran medida la obra literaria martiana. 